\title{
Fracture and Delamination Assessment of Prestressed Composite Concrete for Use with Pipe Jacking Method
}

\author{
Qing Gong, ${ }^{1}$ Hehua Zhu, ${ }^{1,2}$ Zhiguo Yan, ${ }^{1,2}$ Boqi Huang, ${ }^{1}$ Yao Zhang, and Zeyu Dong1 \\ ${ }^{1}$ Department of Geotechnical Engineering, Civil Engineering College, Tongji University, Shanghai 200092, China \\ ${ }^{2}$ State Key Laboratory for Disaster Deduction in Civil Engineering, Tongji University, Shanghai 200092, China \\ Correspondence should be addressed to Hehua Zhu; zhuhehua@tongji.edu.cn
}

Received 24 January 2015; Accepted 17 April 2015

Academic Editor: Timon Rabczuk

Copyright ( 2015 Qing Gong et al. This is an open access article distributed under the Creative Commons Attribution License, which permits unrestricted use, distribution, and reproduction in any medium, provided the original work is properly cited.

\begin{abstract}
Prestressed composite concrete pipe (PCCP) has been widely used in water-transmission line and has been proven with many advantages over pure concrete or steel pipes, such as high performance with relatively low cost for materials as well as simplified installation and construction process. Recent efforts have been made to enable the PCCP structure suitable for pipe jacking method so as to replace the conventional cut and cover method. In this way, the construction time, disturbance to nearby structures, and the cost can be greatly reduced. In this paper, we present the full-scale experimental and numerical studies of PCCP and the evaluation of fracture and delamination behaviour of the structure when it is used with pipe jacking construction method subjected to various jacking forces and ground conditions.
\end{abstract}

\section{Introduction}

Prestressed concrete cylinder pipe (PCCP) has been widely used in water-transmission line and has proven to have many advantages such as high performance price ratio and convenient installation process. PCCP also provides high bearing capacity, long durability, and resistance to corrosion and leakage. The total length of PCCP lines installed in North America is estimated to be $35,150 \mathrm{~km}$ [1]. And two types of PCCP, Embedded Cylinder Pipe and Lined Cylinder Pipe, have been applied since the first application in US in the 1940s [1,2]. Research has been carried out on the operational condition assessment of PCCP with statistical analysis $[1,3-$ $5]$, experiments [6, 7], and numerical modeling $[8,9]$. These studies have shown that PCCP have low levels of damage and low distress rate as compared to conventional concrete pipes.

The cut and cover method is mostly used in PCCP construction. Recently, PCCP structure has been attempted to be used with pipe-jacking construction method, for example, the water-intake project at Langshan Mountain, Nantong city, China. In that project, the pipe has an internal diameter of $2200 \mathrm{~mm}$ and the total jacking length was $340 \mathrm{~m}$. Compared with steel pipe or other jacking pipes, PCCP used as a jacking pipe structure has many advantages, namely, (a) lower cost that PCCP has a much lower steel consumption than steel pipe; (b) faster construction that the spigot and socket structure as well as the flexible docking simplify the construction process; (c) better corrosion resistance since the steel cylinder and wire are protected inside the concrete; (d) improved leakage protection due to the fact that the steel cylinder and rubber gasket installed at the pipe joint under pressure will ensure good resistance to leakage.

The few projects using PCCP for pipe-jacking only use small diameter cross section and for short distance jacking. And the PCCP have been proven to be safe and feasible to be used in pipe jacking method. However, the question rises as to whether the structure remains safe and reliable when the pipe diameter is increased to $3600 \mathrm{~mm}$ and for long jacking distance. In this paper, we aim to study the mechanical behavior of the PCCP under such condition and possible failure mechanism subject to axial and lateral compressive loading conditions.

The present mapper will model the PCCP failure by employing materials models suitable for concrete and steel. The interface failure between layers of the structure will also be taken into account. The numerical methods for the 


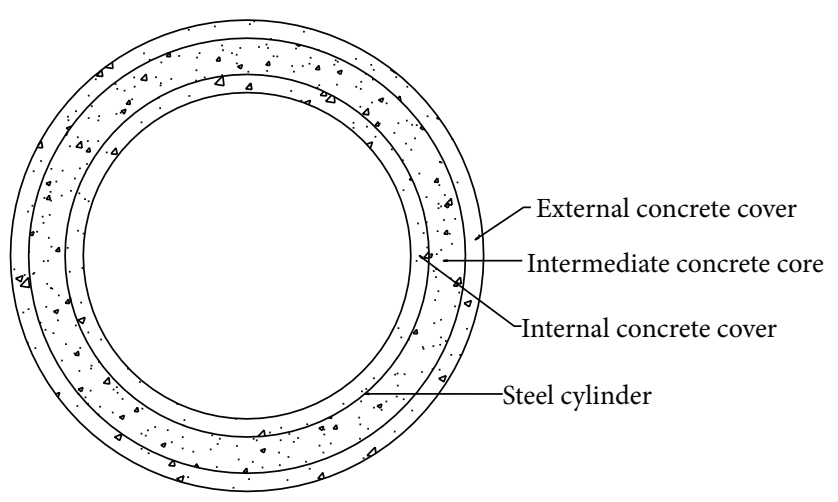

Figure 1: Cross section of the pipe.

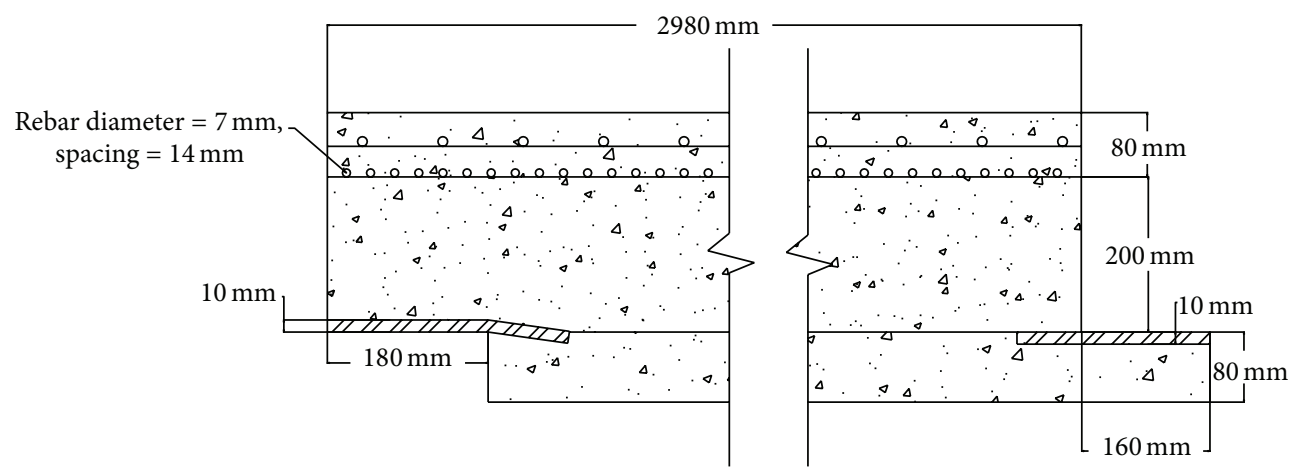

FIGURE 2: Longitudinal cross section of the pipe.

modelling of concrete component/structure failure as well as concrete material include the conventional finite element method and other novel methods for capturing fracture propagation such as meshless methods [10-16], phantomnode method [17], multiscale approach [18, 19], and isometric analysis for fiber optimization [20,21] and among partition of unity based methods [22-27]. In this paper, we will employ the smeared crack model. Note that that stress-strain curve for quasi-brittle materials, for example, concrete, ceramics, and rock typically, goes under a curve with a drop of the stress after the peak stress is reached [28-30]. This phenomenon is termed as softening and can be explained by damage mechanics due to the initiation, growth, and coalescences of micro cracks that reduce the effective cross-sectional area. For more details, the readers are referred to previous works on damage mechanics $[22,31-33]$ and gradient based methods [34-36].

\section{Full Scale Experimental Tests and Results}

The pipe tested in the experiment is shown in Figures 1 and 2. The external and internal diameters of the pipe are $4.32 \mathrm{~m}$ and $3.60 \mathrm{~m}$, respectively. It comprises two main components, namely, concrete external cover and pipe core. The external concrete cover thickness and length were $80 \mathrm{~mm}$ and $2.98 \mathrm{~m}$, respectively. It was reinforced by some configurational steel bar and serves as protect of pipe core. From outside to inside, the pipe core consisted of prestressing wire, intermediate concrete core, steel cylinder, and internal concrete cover. The prestressing wire was spirally wrapped on the intermediate concrete core at close spacing. The stretching control stress of prestressing wire was $1177.5 \mathrm{MPa}$. The steel cylinder thickness was $1.5 \mathrm{~mm}$.

2.1. Loading Conditions and Experiment Process. In order to test the bearing capacity of the pipe and verify the numerical model, a three-edge bearing external load test subjected to ASTM C497 was performed firstly. Then several other tests involving two pipes were conducted with different relative initial angles between the two pipes and different acting oil cylinders in the axial direction. Three types of angle were applied in these tests: no deflection, small deflection $\left(0.3^{\circ}\right)$, and large deflection $\left(0.5^{\circ}\right)$.

In each of the axial loading tests, all of the acting cylinders including the lateral cylinders and axial cylinders were controlled by one loading system, to keep the deflection of two pipes constant during the whole loading process.

\section{The Setup of the Finite Element Model}

3.1. Model Description. To better understand the mechanical characteristics of the pipes and to predict the possible failure modes, we built a 3-dimensional finite element model using commercial software ABAQUS to help us analyze this experiment. The mesh is shown in Figure 3. The model used for three-edge bearing test has finer mesh since it can verify 


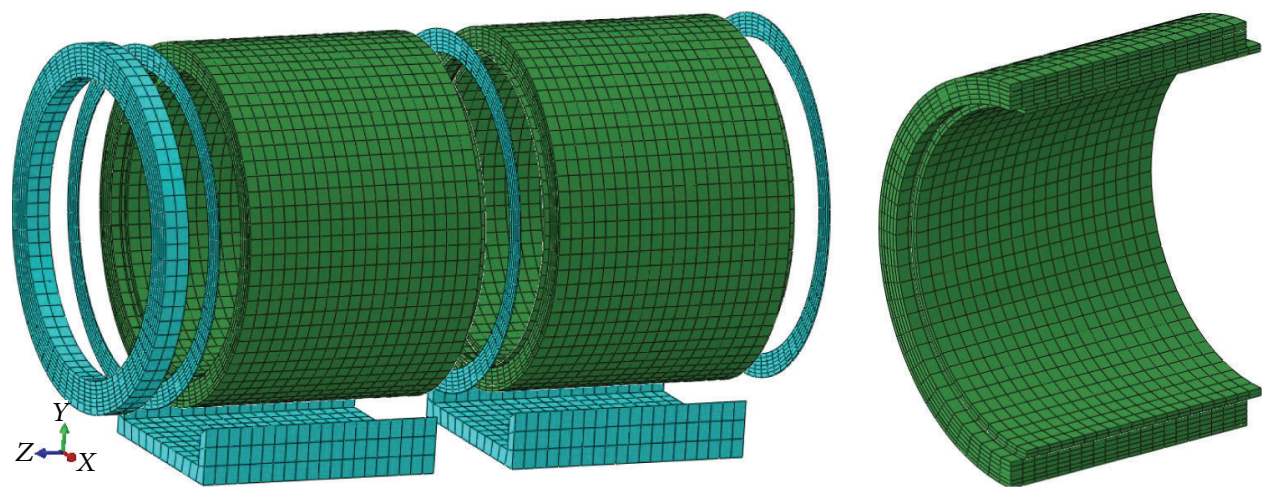

Figure 3: 3D FE model of the experiment.

the material model adopted in our simulation more precisely. In our model of axial loading, two pipes of the same size are used both in experiments and in simulations. For the pipe, the external concrete cover, prestressing wire, intermediate concrete core, steel cylinder, and internal concrete cover were considered. Besides, the iron band and guide rail of pipes were also modeled to reproduce the experiment as real as possible. Concrete damage constitutive model was applied in this model as described in Section 3.2 and other materials were considered as elastic material.

The loading process and boundary condition in our numerical model were applied as similar as possible to that of experiment. In the three-edge bearing test, the pressure at the top of pipe exerted by steel beam above was applied by surface traction, and the batten bracing the pipe was modeled by elastic foundation. In the axial loading tests, the axial forces and lateral forces were applied by concentrated force and pressure, respectively, and the guide rail was simulated by solid model.

In our finite element analysis, to avoid hourglass modes brought by reduced integration, volumetric locking brought by quadratic fully integration and shear locking brought by linear integration, we finally choose 8-node linear solid elements in incompatible modes (C3D8I) to model the concrete, wood cushion, and other solid materials. Prestressing steel was modeled using 2-node linear 3D truss element (T3D2), and the steel cylinder was modeled using the 4-node doubly curved shell element in reduced integration (S4R).

The interfaces between two pipes were considered as follows: the interface between the middle cushion and rear pipe was completely tied together, and the interface between the front pipe and middle cushion was modeled by surfaceto-surface contact in the ABAQUS. There were some other interfaces using the same method to deal with as listed in Table 1 . The other interfaces not mentioned were assumed to have no slide and tied or embedded together, such as the steel cylinder and the concrete surrounding it.

As to the boundary conditions, the base surfaces of two guide rails were fixed in the vertical direction. The rear surface of rear cushion was fixed in the axial direction.

3.2. Mechanical Properties of Materials. The uniaxial stress $(\sigma)$-strain $(\varepsilon)$ relationship of concrete can be depicted as in
TABLE 1: The interfaces using surface-to-surface contact.

\begin{tabular}{lc}
\hline The location of interface & Sliding formulation \\
\hline The front pipe and front cushion & Small sliding \\
The front pipe and middle cushion & Finite sliding \\
Two pipes and their guide rail & Small sliding \\
\hline
\end{tabular}

Figure 4 [37]. The evolution of the damage component $d_{c}$ and $d_{t}$ was determined according to Birtel and Mark [38]. The value of $b_{c}$ and $b_{t}$ in (1) and (3), which should be obtained from test, was referred from their literature [37-39] due to our lack of testing. The tensile damage component $d_{t}$ was slightly adjusted to increase the convergence speed:

$$
\begin{aligned}
& d_{c}=1-\frac{\sigma_{c} E_{0}^{-1}}{\varepsilon_{c}^{\mathrm{pl}}\left(\left(1 / b_{c}\right)-1\right)+\sigma_{c} E_{0}^{-1}}, \\
& b_{c}=\frac{\varepsilon_{c}^{\mathrm{pl}}}{\varepsilon_{c}^{\mathrm{in}}}, \\
& d_{t}=1-\frac{\sigma_{t} E_{0}^{-1}}{\varepsilon_{t}^{\mathrm{pl}}\left(\left(1 / b_{t}\right)-1\right)+\sigma_{t} E_{0}^{-1}}, \\
& b_{t}=\frac{\varepsilon_{t}^{\mathrm{pl}}}{\varepsilon_{t}^{\mathrm{ck}}},
\end{aligned}
$$

where $d_{c}$ is the compressive damage component, $d_{t}$ is the tensile damage component, $\varepsilon_{c}^{\mathrm{pl}}$ is the plastic compressive strain, $\varepsilon_{t}^{\mathrm{pl}}$ is the plastic tensile strain, $\varepsilon_{c}^{\text {in }}$ denotes the inelastic compressive strain, and $\varepsilon_{t}^{\text {in }}$ is the inelastic tensile strain.

A summary of the mechanism properties of the material used in the FE model is listed in Table 2. Concrete used in each layer of the pipe is the same material and its properties have been tested in laboratory, including Young's modulus, characteristic value of uniaxial compressive, and tensile strength. 
TABLE 2: Material parameters.

\begin{tabular}{lccc}
\hline Material & Young's modulus $(\mathrm{GPa})$ & Yield stress $(\mathrm{MPa})$ & Density $\left(\mathrm{kg} / \mathrm{m}^{3}\right)$ \\
\hline Concrete & 35.5 & 32.4 (compressive)/2.64 (tensile) & 2500 \\
Steel cylinder & 206 & 300 & 7800 \\
Prestressing wire & 205 & 1570 & 7800 \\
Configurational steel bar & 190 & 500 & 7800 \\
Wood cushion & 0.4 & - & - \\
Guide rail & 200 & - & - \\
Iron band & 1000 & - & - \\
\hline
\end{tabular}

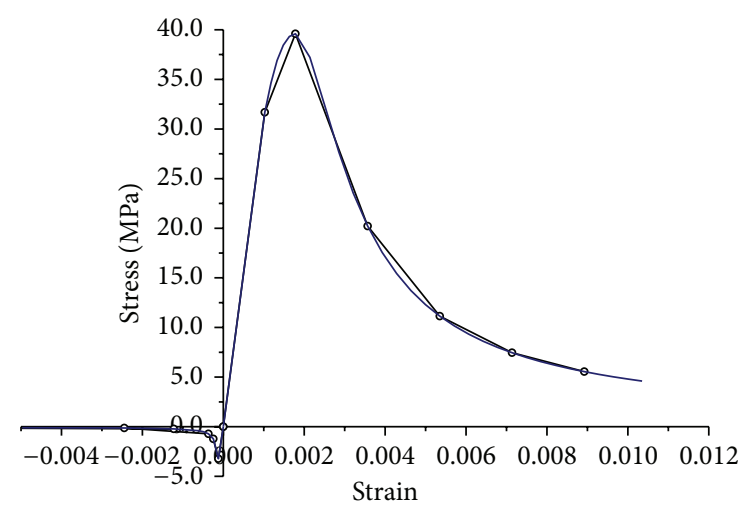

FIGURE 4: Concrete uniaxial strain-stress relationship subjected to tension and compression.

\section{Numerical Modelling and Validation with Experiments}

The numerical model is set up corresponding to the experiments. Some local output parameters which cannot be measured accurately such as strain and stress can therefore be obtained from the FE modelling and can be used for the reference of design and construction.

4.1. Initial Stress State. The prestressing of the pipe is applied using equivalent temperature descent method [40]. The steel wire was given a thermal expansion $\alpha_{s}$ of $1 e-5$ and its elastic modulus $E_{s}$ is $205 \mathrm{GPa}$. Thus, the stress of wire in our model can be adjusted by changing the temperature descent whose initial value can be calculated as

$$
\Delta T=\frac{\sigma_{\mathrm{sw}}}{\alpha_{s} E_{s}} .
$$

The effective prestressing force $\sigma_{\mathrm{sw}}$ considering all kinds of prestressing loss by design is $1003 \mathrm{MPa}$, which is also the target value of the wire's stress. The initial stress of steel wire after the temperature descent as shown in Figure 5 is precise enough for our analysis. Figure 6 depicts the initial axial stress of concrete of the pipe. The initial condition takes into account the prestressing and gravity. It is noticed that the maximum tensile axial stress exists at the inner wall near the spigot and the value is about $2.1 \mathrm{MPa}$. Actually, some micro cracks were found at the inner wall near the spigot in axial loading tests, but when and how these cracks formed and

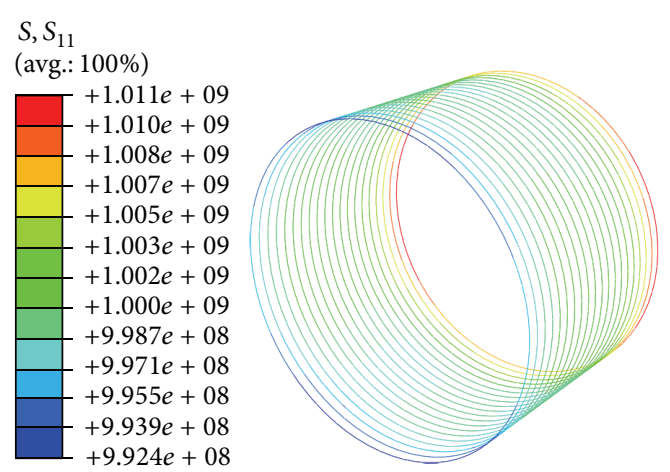

FIGURE 5: Initial stress of prestressing wire.

developed cannot be confirmed because they were noticed after all the tests.

4.2. Analysis on the Three-Edge Bearing Test. The three-edge bearing test, which aimed at determining the strength of pipe withstanding the vertical crushing loads, also established the load-strain curve of many parts of the pipe and verified our numerical models. The maximum vertical loading amount was $2600 \mathrm{kN}$ in our model. Figure 7 shows the load-strain (circumferential) curve of several points of the inner wall at section 1 from test and numerical results. It is evident that the numerical model for three-edge bearing test matches well with test.

Figure 8 depicts the final damage distribution of the pipe. The damage area is mainly located at the concrete interior of pipe top and bottom and the exterior of pipe waist. These areas were exactly where cracks propagated. Since the concrete damage plastic model would not reflect cracks on concrete directly, we suggest taking 11 times the tensile strain of concrete as the criterion for crack initiation, which works out $818 \mu \varepsilon$ in our model, because this is when we first saw cracks in the test.

A remarkable phenomenon during the test was the delamination of exterior concrete and intermediate concrete core. To analyze this phenomenon, the radial stress and circumferential shear stress were illustrated in Figure 9. It can be seen that the maximum radial stress is rather low $(0.40 \mathrm{MPa})$ but the maximum shear stress is a high level $(4.47 \mathrm{MPa})$. We can conclude that this delamination resulted from the shear failure in the three-edge bearing test. More experiments are needed to determine the shear strength 


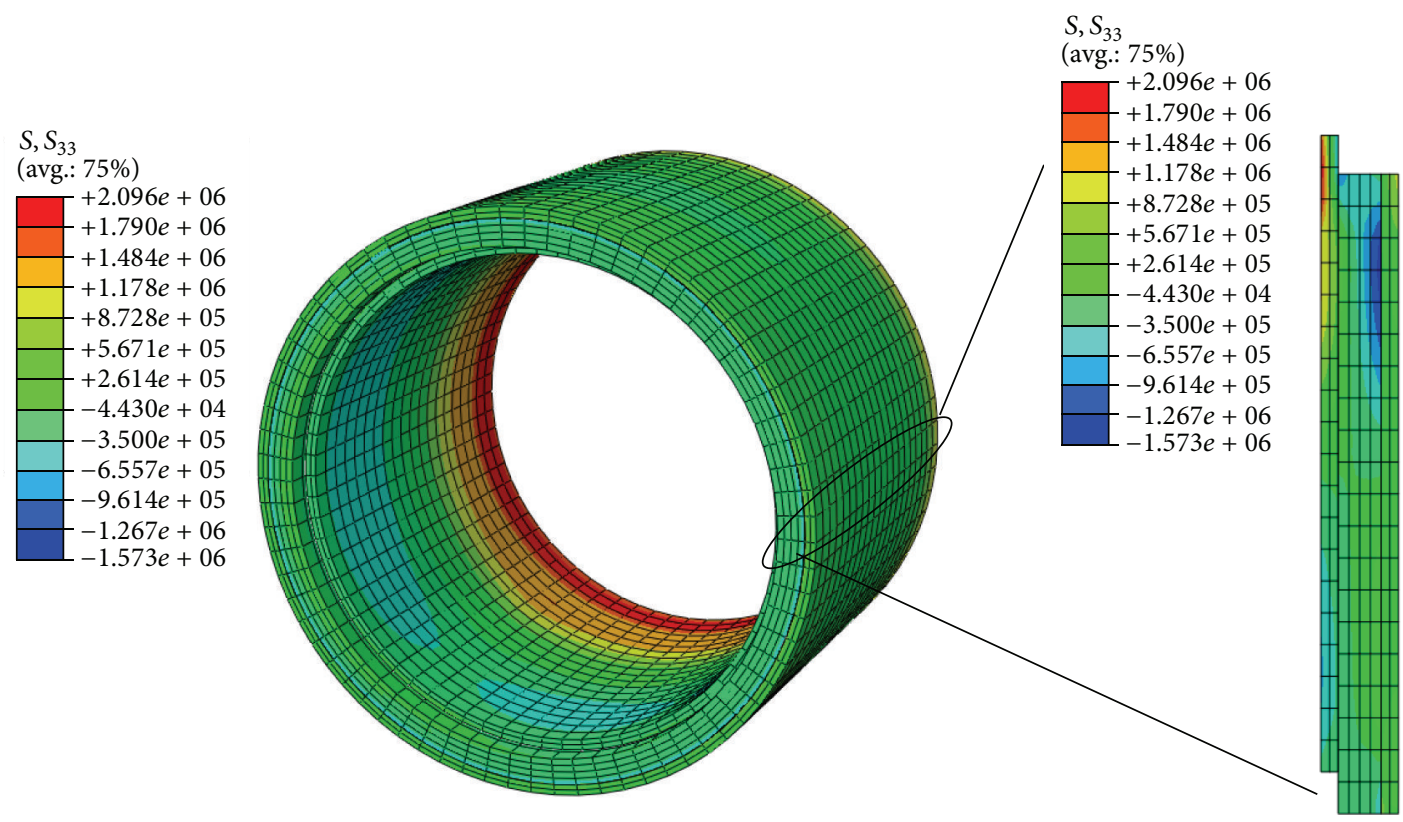

FIGURE 6: Initial radial stress of concrete.

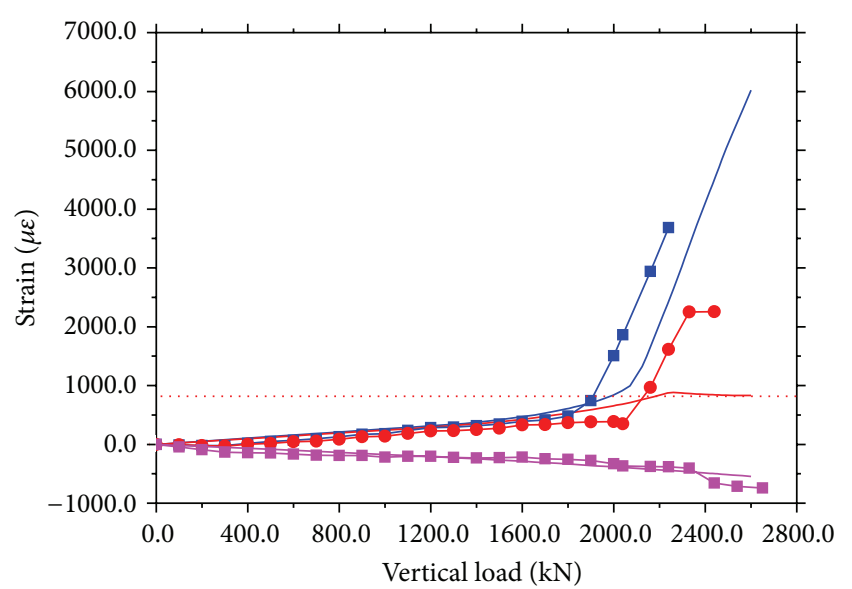

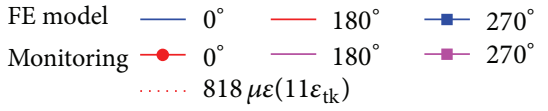

FIGURE 7: Circumferential strain of inner wall.

of separately pouring concrete with prestressing steel wire between them.

4.3. Analysis on the Axial Loading Test. In this section the axial loading test was analyzed in four aspects: the concrete, the interface between external cover and intermediate concrete core, the prestressing wire, and the influence of wood cushion. These numerical analyses were verified by monitor data.

4.3.1. The Concrete Assessment of Pipes. Figure 10 shows the comparison of axial strain of 3 concrete parts at $90^{\circ}$ of section 1 of the front pipe from the FE results and monitoring in test
2. It can be seen from the figure that relationship between the axial strain and axial loading force is approximately linear. And the FE results are well consistent with the monitoring data. The final errors of three concrete parts are $0.8 \%$ for internal concrete cover, $1.4 \%$ for intermediate concrete core, and $5.6 \%$ for external concrete cover. The FE model is confirmed by the experimental results.

The axial stress contour plot of tests 1, 2, and 5 was shown in Figures 11, 12, and 13. The maximum axial compress stress in tests 1,2 , and 5 is $8.3 \mathrm{MPa}, 8.9 \mathrm{MPa}$, and $25.7 \mathrm{MPa}$, respectively. The maximum axial tensile stresses in test 1 , 2, and 5 are $1.70 \mathrm{MPa}, 1.74 \mathrm{MPa}$, and $2.35 \mathrm{MPa}$, respectively. It is apparent that when two pipes are loaded axially with even very little deflection angle (close to $0.3^{\circ}$ in test 5 ), the maximum axial compressive stress and tensile stress would significantly increase compared with when the pipes connected without deflection angle.

For the axial tensile stress, the initial value at the inner wall of the spigot of the pipe is $2.10 \mathrm{MPa}$, which is close to the limit tensile strength of the concrete. And the tensile stress decreases when loaded without angle whereas increases to $2.35 \mathrm{MPa}$ when loaded with angle. The deflection angle does not have impact on the maximum tensile stress (see Figure 14). The prestressing force makes the pipe core contract except the spigot, inducing the tensile stress concentration at the spigot. The axial eccentric force increases the stress and may cause local structure damage.

For the axial compress stress, in tests 1 and 2, the maximum axial compress stresses occur at the intermediate concrete core near the socket. In test 5 the maximum compress stress is located at the concrete external surface near the spigot at the left side, the same side where the center of axial eccentric force is located. Other tests where pipes were loaded with certain angle have similar axial stress distribution like test 5 . 

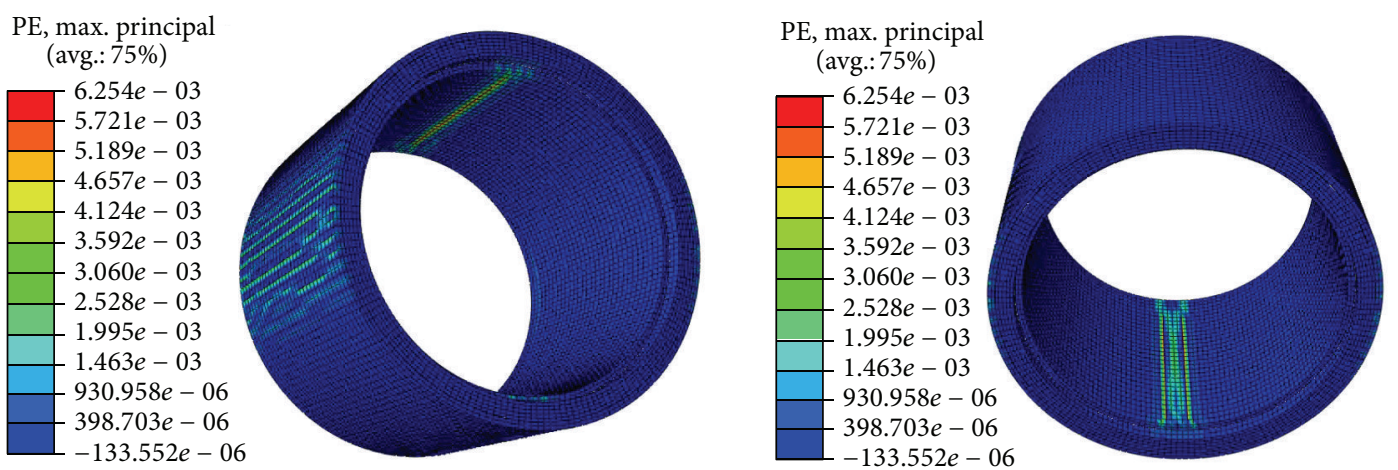

FIGURE 8: Damage distribution of concrete in three-edge bearing test.

S, $S_{11}($ CSYS-1)
(avg.: $75 \%)$

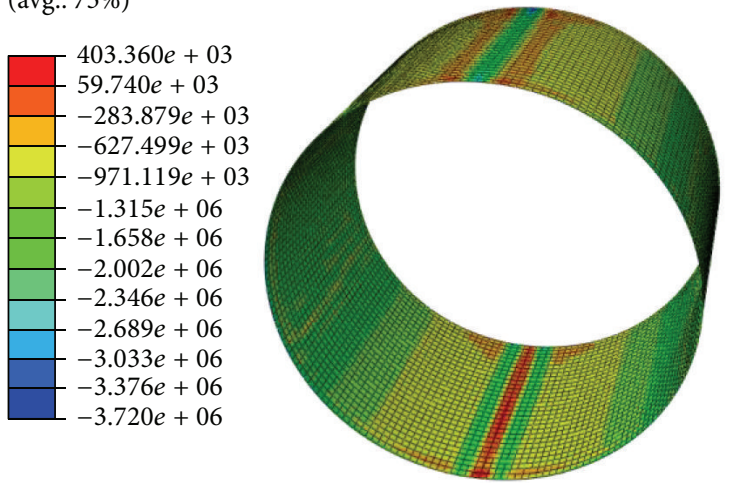

(a) Radial stress

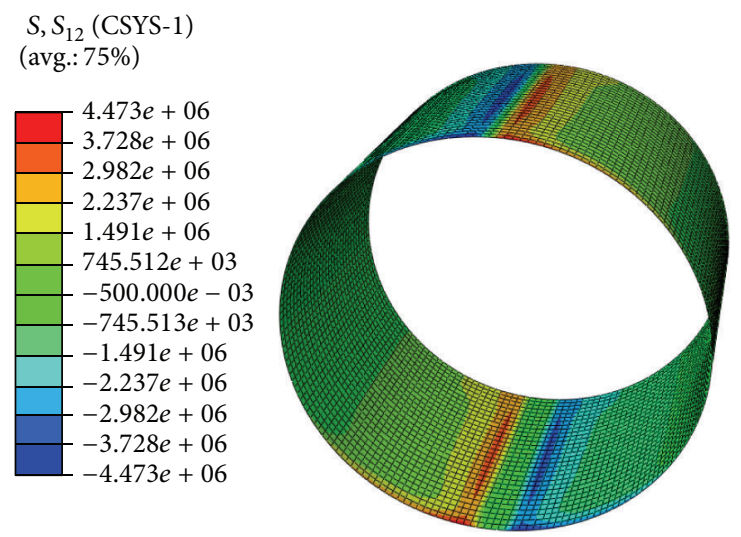

(b) Circumferential shear stress

FIGURE 9: Stress at the interface of exterior concrete and intermediate concrete core.

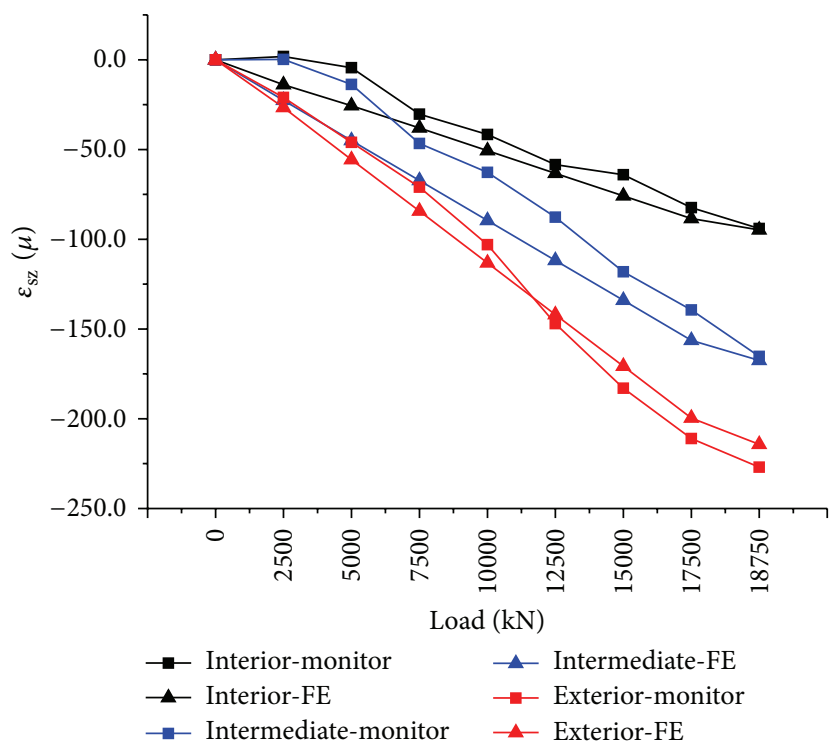

FIgURe 10: Axial strain of concrete at $90^{\circ}$, section 1. 

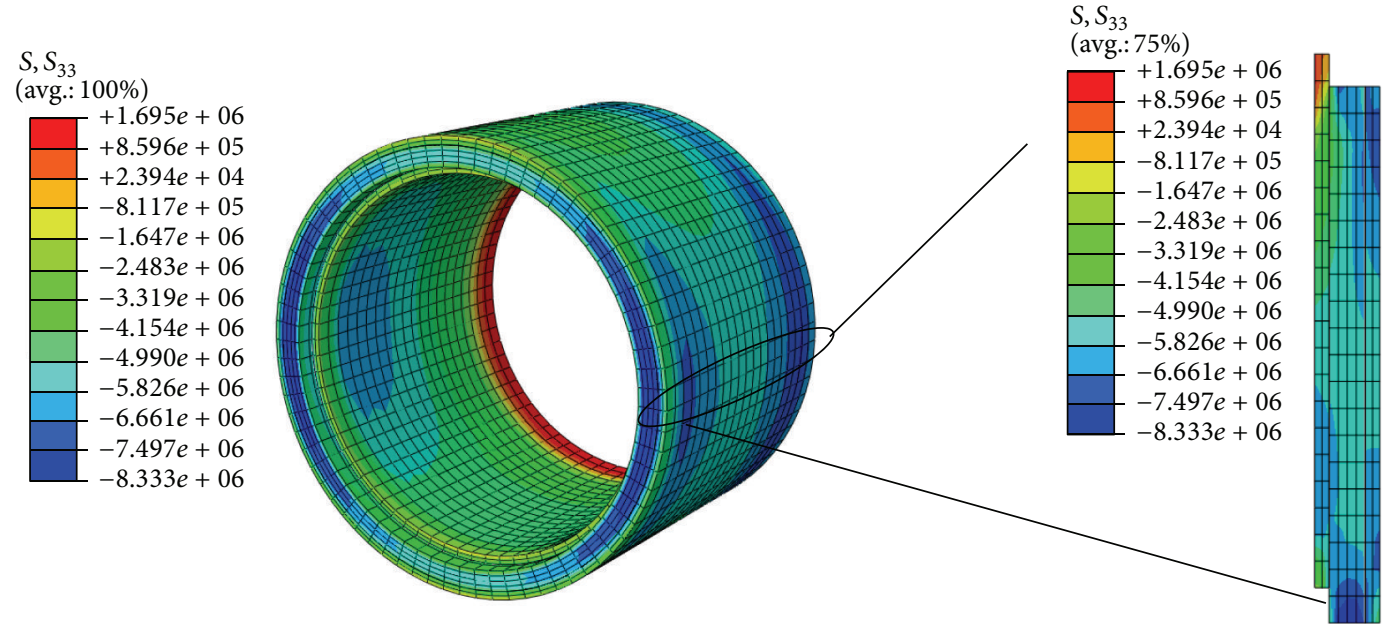

FIGURE 11: Radial stress of the front pipe in test 1.

$S, S_{33}$
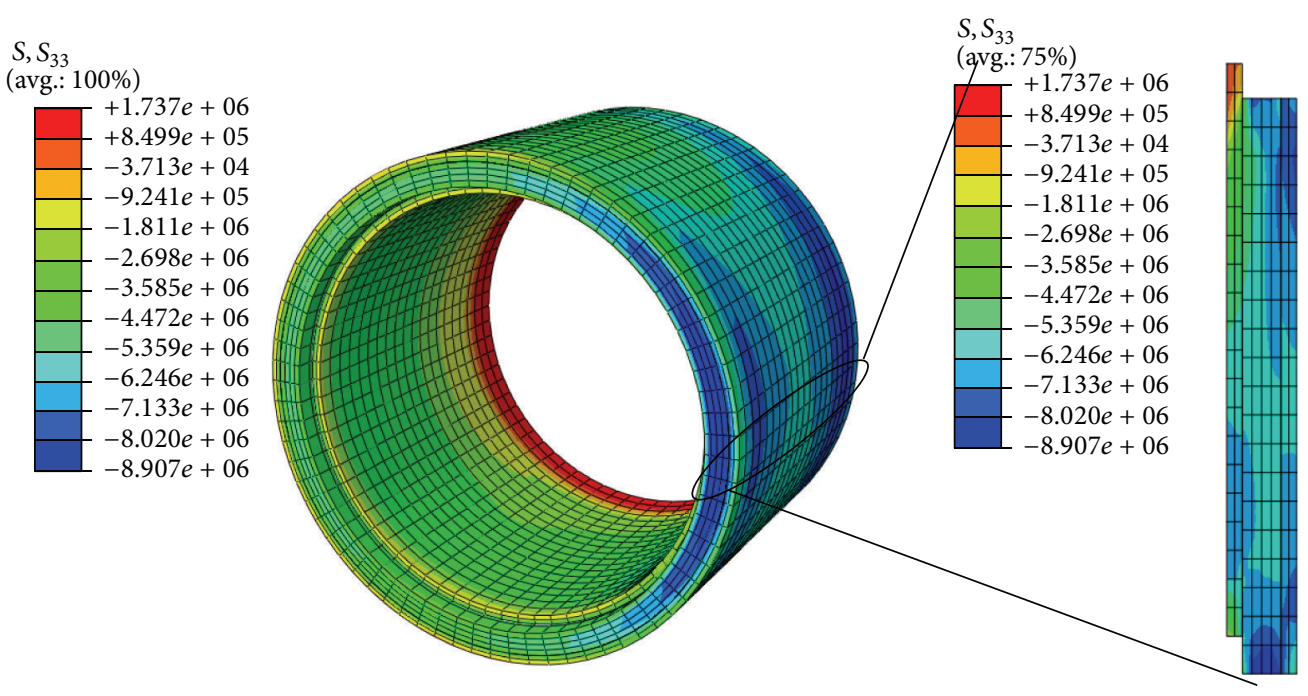

FIgURE 12: Radial stress of the front pipe in test 2.

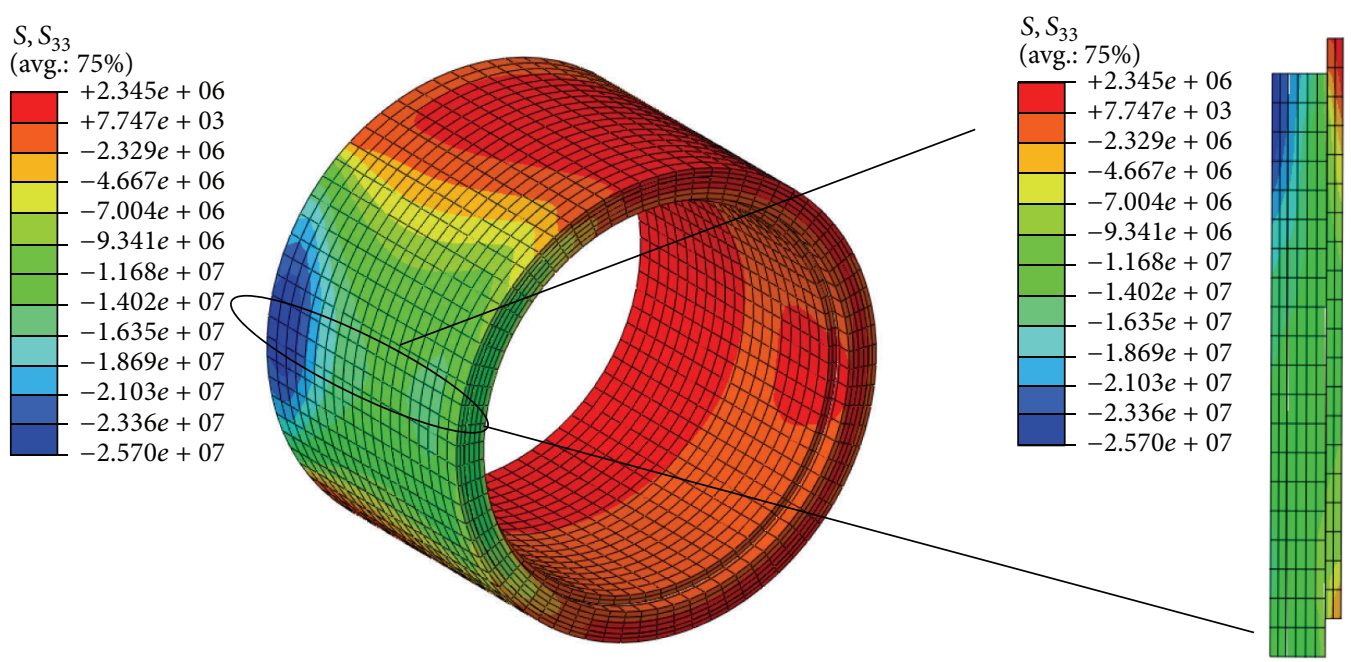

FIGURE 13: Radial stress of the front pipe in test 5. 


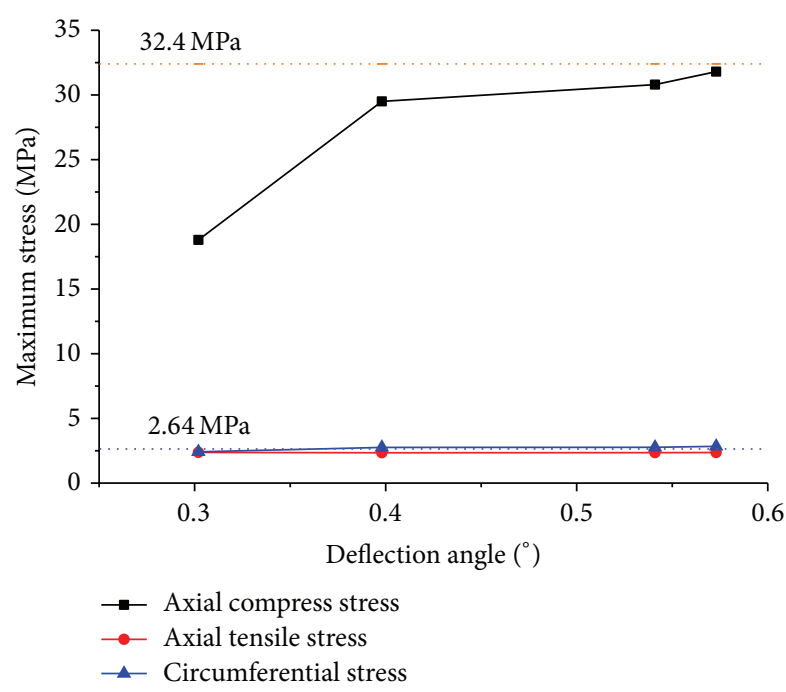

FIGURE 14: The maximum stress of concrete under different angles (test 7 10).

Figure 14 shows the maximum stress in concrete for tests 7 to 10 . It can be seen that the maximum axial compress stress grows with the deflection angle. The largest value appears in test 10 and is $31.8 \mathrm{MPa}$, close to the characteristic value of concrete compressive strength $(32.4 \mathrm{MPa})$.

The circumferential stress contour of test 5 is depicted in Figure 15 . The maximum tensile stress is $2.46 \mathrm{MPa}$, fairly close to the characteristic tensile strength of concrete $(2.64 \mathrm{MPa})$. It is localized at external concrete cover near the socket. The concentrated circumferential tensile stress is due to the distortion and inhomogeneous deformation of the pipe as shown in Figure 16. Other tests that are loaded with angle have similar circumferential stress distribution like test 5 . From Figure 14, the maximum circumferential tensile stress grows slightly with the deflection angle. The largest maximum circumferential tensile stress occurs in test 10 and the value is $2.84 \mathrm{MPa}$, over the characteristic value of concrete tensile strength. Protective measures are needed such as a steel collar wrapped on the stress concentration area.

4.3.2. The Delamination between External Cover and Intermediate Concrete Core. This section presents the analyses on the surface between external concrete cover and intermediate concrete core. This interface is important because that is also where the prestressing wire is located. Once the interface delaminates, the prestressing wire might be damaged due to corrosion. Zarghamee et al. [6] conducted experiments to analyze the parameters influencing the radial tensile strength of mortar coating. In their tests, the specimens consisted of the mortar and weldment reinforced by prestressing wire. In our experiments, the covering layer is concrete instead of mortar, and the prestressed part is concrete instead of weldment. Besides, the measured parameter is radial strain instead of radial stress. Figure 17 compares the radial strain on the surface at $270^{\circ}$, section 1 in test 5 . The radial strain in FE model is slightly larger than that monitored in our experiment. The final error is about $5.0 \%$.
Figure 18 illustrates the radial strain from FE model near the surface between concrete external surface and intermediate concrete core of the front pipe in test 5. The maximum radial strain is about $140 \mu \varepsilon$ located at $270^{\circ}$ near the spigot. Large radial strain also exists near the socket. That is because the socket end of the pipe, which is connected to the spigot end, only consists layers of intermediate concrete core and external concrete cover. Therefore, the internal concrete cover does not belong to the prestressed part of the pipe.

Other tests on deflection angle show similar strain results as in test 5 . The maximum radial strain grows significantly with the deflection angle. And the highest value of maximum radial strain is approximately $247 \mu \varepsilon$ in test 10 , which is almost 1.8 times as much as in test 5 .

The ultimate tensile strain of the concrete material used in the experiment is $76.5 \mu \varepsilon$, and the maximum radial strains from FE model are much larger than that of about 1.6 times in test 5 and 3.25 times in test 10 . No obvious delamination phenomena appeared in all tests. However, cracks cannot be detected if they initiated inside. The bond force at the surface can be strengthened like embedding ribbed steel bars to link two concrete layers. This is due to the limitation in the present model considering the normal contact and slips between steel and concrete.

4.3.3. Analysis on the Prestressing Wire. Figure 19 depicts the stress increment of prestressing wire in test 5 from FE model. The stress increment was calculated from the time the axial eccentric load was exerted. In this figure, positive stress increment which means stress growth, appears at the same side where the eccentric load was applied, and negative stress increment which means prestress loss occurs at the other side. The maximum stress growth is $22.2 \mathrm{MPa}$, and the maximum prestress loss is $20.7 \mathrm{MPa}$. Other tests show similar stress distribution like test 5 . The extreme values are scattered due to its high sensitivity to the lateral loads, nonetheless the values are still relatively low to induce prestress loss of the pipe.

From the results it can be seen that the damage of prestressing wire should not occur during substantial pipejacking process, since the load conditions in experiment are way more critical than the actual jacking conditions.

4.3.4. Analysis on the Influence of Elastic Modulus of Wood Cushion. Only few literatures have been devoted to the study of the influence of cushion on the mechanical characteristics of the jacking pipes. Wang [41] indicates that the minimum radius of curve in pipe-jacking is inversely proportional to the thickness of wood cushions. The configuration of curved pipe-jacking is shown schematically in Figure 20. However, in his study cushions have not been considered in the model.

A new FE model is established in which the elastic modulus of wood cushion is set as $200 \mathrm{MPa}$, half as large as before. Other parameters and conditions are the same as the FE model simulating test 5.

After Young's modulus of the wood cushion has been changed, the stress distribution of concrete is almost the same as the previous modelling results. The maximum axial compressive stress reaches $23.2 \mathrm{MPa}$, about $10 \%$ less than 


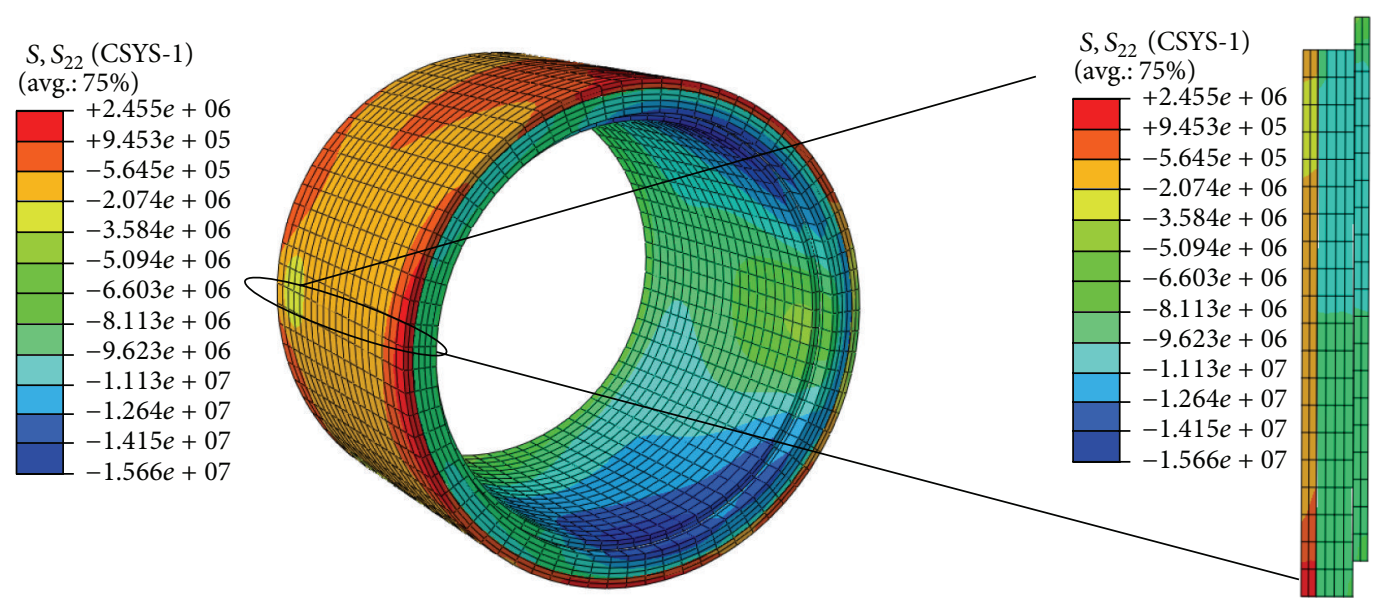

FIgURE 15: Circumferential stress of the front pipe in test 5.

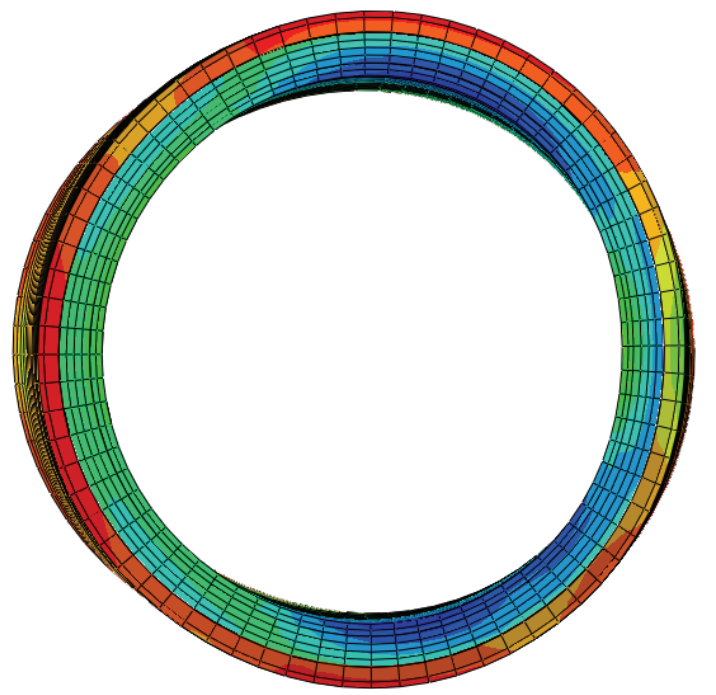

FIGURE 16: Distortion of the front pipe in test 5 (deformation scale factor: 100).

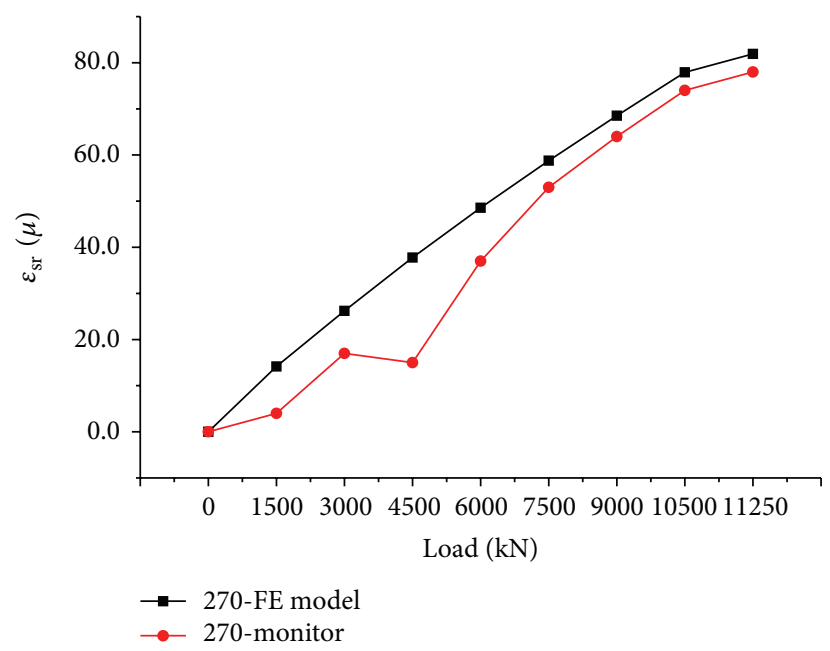

FIGURE 17: Radial strain on the surface at $270^{\circ}$, cross section 1 .
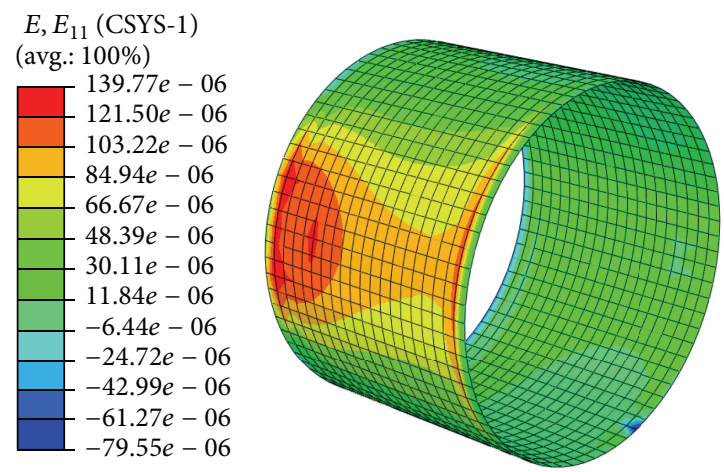

FIGURE 18: Radial strain at the surface of the front pipe.

the previous result. The maximum axial tensile stress is 2.35 MPa, remaining constant compared to the previous result. The maximum radial strain at the surface between external concrete cover and intermediate concrete core drops to $128 \mu \varepsilon$, about $9 \%$ smaller. The maximum stress growth of prestressing wire turns into $20.7 \mathrm{MPa}$, which is around $7 \%$ less and the maximum prestress loss remains unchanged value of 20.7 MPa. The safety of the structure of pipe increases when the stiffness of the wood cushion decreases. The quantitative analysis of the relation between the wood cushion and the mechanical performance of the pipe considering the material hardening properties and randomness remains to be investigated.

\section{Conclusions}

In this paper, a study on the mechanical performance of PCCP used as a pipe-jacking structured by both experimental tests and FE modelling is presented. A three-dimensional FE model is established for the fracture and delamination analysis of PCCP in a three-edge bearing test and several axial loading tests. The results are verified by experimental data. 


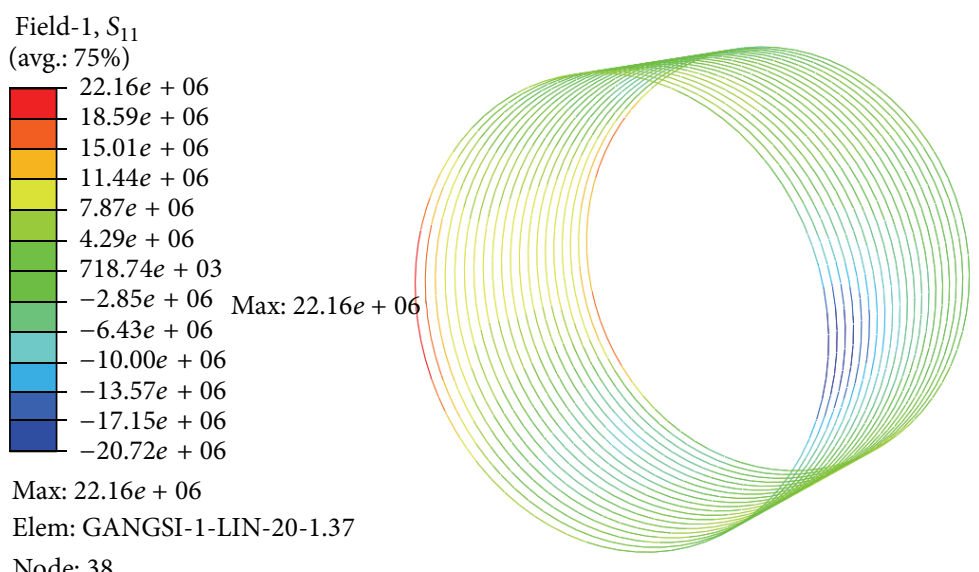

FIGURE 19: Stress increment of prestressing wire in test 5.

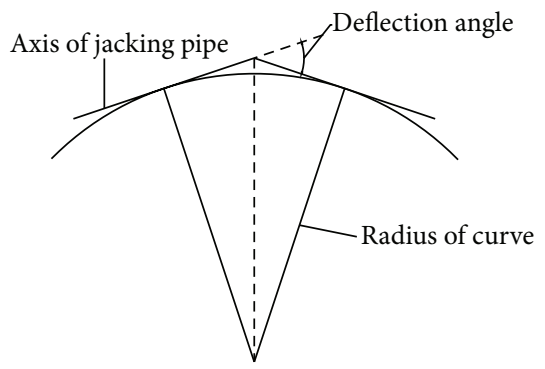

FIGURE 20: Schematic diagram of curved pipe jacking.

A number of structural problems are highlighted and suggestions are given accordingly. Firstly, the initial axial tensile stress at the inner wall of the spigot of the pipe is high and may cause circumferential cracks during pipe-jacking, which has been reproduced in full scale experiments. The axial eccentric force increases the tensile stress and results in the local structure damage. Secondly, the deflection angle in pipejacking project for this pipe should not exceed $0.5^{\circ}$ during the piping process. Thirdly, the prestressing wire exhibits low stress growth and low prestress loss during the loading. And it will not be damaged due to pipe-jacking process. Finally, softer wood cushion will improve the structure safety of the pipe. Further study is needed to determine the relationship between material property of cushion and the mechanical characteristics of pipe, providing suggestions on the design of cushion.

\section{Conflict of Interests}

The authors declare that there is no conflict of interests regarding the publication of this paper.

\section{Acknowledgments}

The authors gratefully acknowledge the supports from the NSFC Program (51379147), the National Basic Research Program of China (973 Program: 2011CB013800), the Program for Changjiang Scholars and Innovative Research Team in University (PCSIRT, IRT1029), and Shanghai Chenguang Program (12CG20).

\section{References}

[1] S. M. Semanuik and B. Mergelas, "Comparison of identified distress in CCP pipelines operated by water utilities in North America," in Pipelines 2006: Service to the Owner-Proceedings of the 2006 Pipeline Division Specialty Conference, pp. 1-8, 2006.

[2] A. E. Romer, Failure of Prestressed Concrete Cylinder Pipe, AWWA Research Foundation, 2008.

[3] M. S. Higgins, A. Stroebele, and S. Zahidi, "Numbers don't lie: PCCP performance and deterioration based on a statistical review of a decade of condition assessment data," Bridges, vol. $10,2014$.

[4] D. Wittas, "Statistical analysis of condition assessment data and prediction of future performance of PCCP," in Proceedings of the Pipelines Conference, pp. 160-169, Seattle, Wash, USA, July 2011.

[5] M. S. Zarghamee, R. P. Ojdrovic, and P. D. Nardini, "Prestressed concrete cylinder pipe condition assessment-what works, what doesn't, what's next," in Proceedings of the Pipelines: A Sound Conduit for Sharing Solutions, pp. 182-194, Water Research Foundation, Denver, Colo, USA, July 2011.

[6] M. S. Zarghamee, F. J. Heger, and W. R. Dana, "Experimental evaluation of design methods for prestressed concrete plpe," Journal of Transportation Engineering, vol. 114, pp. 635-655, 1988.

[7] M. S. Zarghamee, R. P. Ojdrovic, and W. R. Dana, "Coating delamination by radial tension in prestressed concrete pipe. I: experiments," Journal of Structural Engineering, vol. 119, no. 9, pp. 2701-2719, 1993.

[8] S. Ge and S. K. Sinha, "Evaluation of Condition of Prestressed Concrete Cylidner Pipe (PCCP) using numerical simulation," Proceedings of the Water Environment Federation, vol. 2011, no. 12, pp. 3952-3970, 2011.

[9] H. Xiong, P. Li, and Q. Li, "FE model for simulating wirewrapping during prestressing of an embedded prestressed concrete cylinder pipe," Simulation Modelling Practice and Theory, vol. 18, no. 5, pp. 624-636, 2010.

[10] N. Nguyen-Thanh, J. Muthu, X. Zhuang, and T. Rabczuk, "An adaptive three-dimensional RHT-splines formulation in linear 
elasto-statics and elasto-dynamics," Computational Mechanics, vol. 53, no. 2, pp. 369-385, 2014.

[11] T. Rabczuk and T. Belytschko, "A three-dimensional large deformation meshfree method for arbitrary evolving cracks," Computer Methods in Applied Mechanics and Engineering, vol. 196, no. 29-30, pp. 2777-2799, 2007.

[12] X. Zhuang, C. Augarde, and S. Bordas, "Accurate fracture modelling using meshless methods, the visibility criterion and level sets: formulation and 2D modelling," International Journal for Numerical Methods in Engineering, vol. 86, no. 2, pp. 249268, 2011.

[13] X. Zhuang and Y. Cai, "A meshless local petrov-galerkin shepard and least-squares method based on duo nodal supports," Mathematical Problems in Engineering, vol. 2014, Article ID 806142, 11 pages, 2014.

[14] X. Zhuang, Y. Cai, and C. Augarde, "A meshless sub-region radial point interpolation method for accurate calculation of crack tip fields," Theoretical and Applied Fracture Mechanics, vol. 69, pp. 118-125, 2014.

[15] X. Zhuang, C. Heaney, and C. Augarde, "On error control in the element-free Galerkin method," Engineering Analysis with Boundary Elements, vol. 36, no. 3, pp. 351-360, 2012.

[16] X. Zhuang, H. Zhu, and C. Augarde, "An improved meshless Shepard and least squares method possessing the delta property and requiring no singular weight function," Computational Mechanics, vol. 53, no. 2, pp. 343-357, 2014.

[17] N. Vu-Bac, H. Nguyen-Xuan, L. Chen et al., "A phantom-node method with edge-based strain smoothing for linear elastic fracture mechanics," Journal of Applied Mathematics, vol. 2013, Article ID 978026, 12 pages, 2013.

[18] H. Talebi, M. Silani, and T. Rabczuk, "Concurrent multiscale modelling of three dimensional crack and dislocation propagation," Advances in Engineering Software, vol. 80, pp. 82-92, 2015.

[19] S. Ghorashi, N. Valizadeh, S. Mohammadi, and T. Rabczuk, "Tspline based XIGA for fracture analysis of orthotropic media," Computers \& Structures, vol. 147, pp. 138-146, 2015.

[20] N. Nguyen-Thanh, N. Valizadeh, M. N. Nguyen et al., "An extended isogeometric thin shell analysis based on KirchhoffLove theory," Computer Methods in Applied Mechanics and Engineering, vol. 284, pp. 265-291, 2015.

[21] Y. Jia, Y. Zhang, G. Xu, X. Zhuang, and T. Rabczuk, "Reproducing kernel triangular B-spline-based FEM for solving PDEs," Computer Methods in Applied Mechanics and Engineering, vol. 267, pp. 342-358, 2013.

[22] P. Areias, T. Rabczuk, and P. P. Camanho, "Initially rigid cohesive laws and fracture based on edge rotations," Computational Mechanics, vol. 52, no. 4, pp. 931-947, 2013.

[23] Y. Cai, X. Zhuang, and C. Augarde, "A new partition of unity finite element free from the linear dependence problem and possessing the delta property," Computer Methods in Applied Mechanics and Engineering, vol. 199, no. 17-20, pp. 1036-1043, 2010.

[24] Y. Cai, X. Zhuang, and H. Zhu, "A generalized and efficient method for finite cover generation in the numerical manifold method," International Journal of Computational Methods, vol. 10, no. 5, Article ID 1350028, 19 pages, 2013.

[25] T. Rabczuk, S. Bordas, and G. Zi, "On three-dimensional modelling of crack growth using partition of unity methods," Computers \& Structures, vol. 88, no. 23-24, pp. 1391-1411, 2010.

[26] T. Rabczuk, R. Gracie, J.-H. Song, and T. Belytschko, "Immersed particle method for fluid-structure interaction," International
Journal for Numerical Methods in Engineering, vol. 81, no. 1, pp. 48-71, 2010.

[27] X. Y. Zhuang, R. Q. Huang, H. H. Zhu, H. Askes, and K. Mathisen, "A new and simple locking-free triangular thick plate element using independent shear degrees of freedom," Finite Elements in Analysis and Design, vol. 75, pp. 1-7, 2013.

[28] W. Wu, H. Zhu, X. Zhuang, G. Ma, and Y. Cai, "A multi-shell cover algorithm for contact detection in the three dimensional discontinuous deformation analysis," Theoretical and Applied Fracture Mechanics, vol. 72, pp. 136-149, 2014.

[29] H. Zhu, X. Zhuang, Y. Cai, and G. Ma, "High rock slope stability analysis using the enriched meshless Shepard and least squares method," International Journal of Computational Methods, vol. 8, no. 2, pp. 209-228, 2011.

[30] X. Zhuang, J. Chun, and H. Zhu, "A comparative study on unfilled and filled crack propagation for rock-like brittle material," Theoretical and Applied Fracture Mechanics, vol. 72, pp. 110-120, 2014.

[31] P. Areias, T. Rabczuk, and D. Dias-da-Costa, "Element-wise fracture algorithm based on rotation of edges," Engineering Fracture Mechanics, vol. 110, pp. 113-137, 2013.

[32] Z. P. Bazant and G. Pijaudier-Cabot, "Nonlocal continuum damage, localization instability and convergence," Journal of Applied Mechanics, vol. 55, no. 2, pp. 287-293, 1988.

[33] C. A. Duarte, D.-J. Kim, and I. Babuška, "A global-local approach for the construction of enrichment functions for the generalized FEM and its application to three-dimensional cracks," in Advances in Meshfree Techniques, vol. 5 of Computational Methods in Applied Sciences, pp. 1-26, Springer, Amsterdam, The Netherlands, 2007.

[34] R. de Borst, M. A. Gutiérrez, G. N. Wells, J. J. C. Remmers, and H. Askes, "Cohesive-zone models, higher-order continuum theories and reliability methods for computational failure analysis," International Journal for Numerical Methods in Engineering, vol. 60, no. 1, pp. 289-315, 2004.

[35] R. de Borst, "Fracture in quasi-brittle materials: a review of continuum damage-based approaches," Engineering Fracture Mechanics, vol. 69, no. 2, pp. 95-112, 2002.

[36] R. de Borst, J. Pamin, and M. G. D. Geers, "On coupled gradient-dependent plasticity and damage theories with a view to localization analysis," European Journal of Mechanics A: Solids, vol. 18, no. 6, pp. 939-962, 1999.

[37] GB 50010-2010 Code for Design of Concrete Structures, Architecture and Building Press, Beijing, China, 2010.

[38] V. Birtel and P. Mark, "Parameterised finite element modelling of RC beam shear failure," in Proceedings of the 2006 ABAQUS User's Conference, pp. 95-108, Boston, Mass, USA, May 2006.

[39] Z. P. Bažant and M. Jirásek, "Nonlocal integral formulations of plasticity and damage: survey of progress," Journal of Engineering Mechanics, vol. 128, no. 11, pp. 1119-1149, 2002.

[40] Z. Caixiu, Finite element analysis of prestressed concrete cylinder pipe (PCCP) [M.S. thesis], Tianjin University, 2006.

[41] C. Wang, "Primary study of curved tunneling by pipe jacking," Special Structures, vol. 4, 1998. 


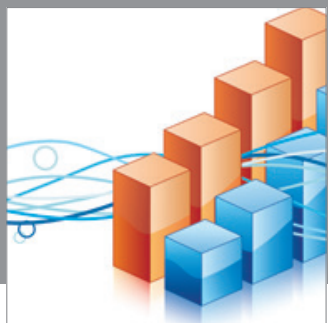

Advances in

Operations Research

mansans

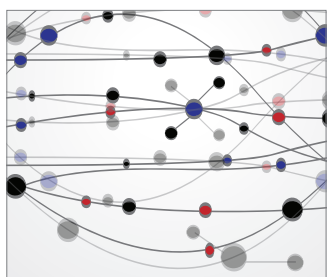

The Scientific World Journal
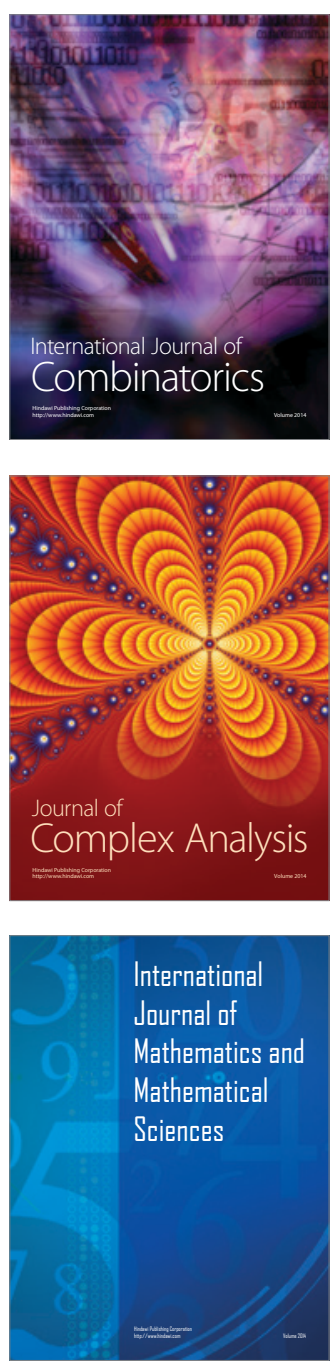
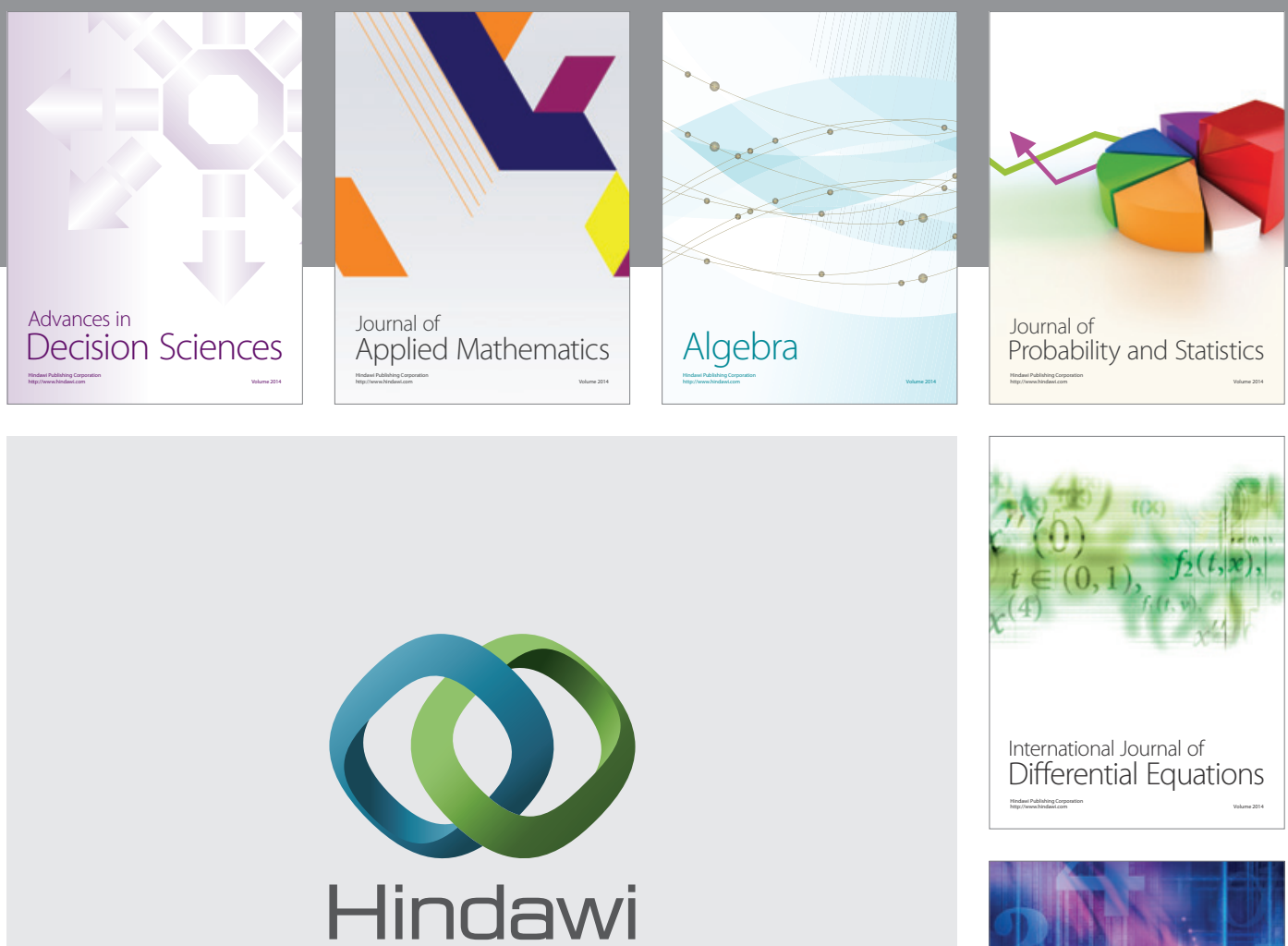

Submit your manuscripts at http://www.hindawi.com
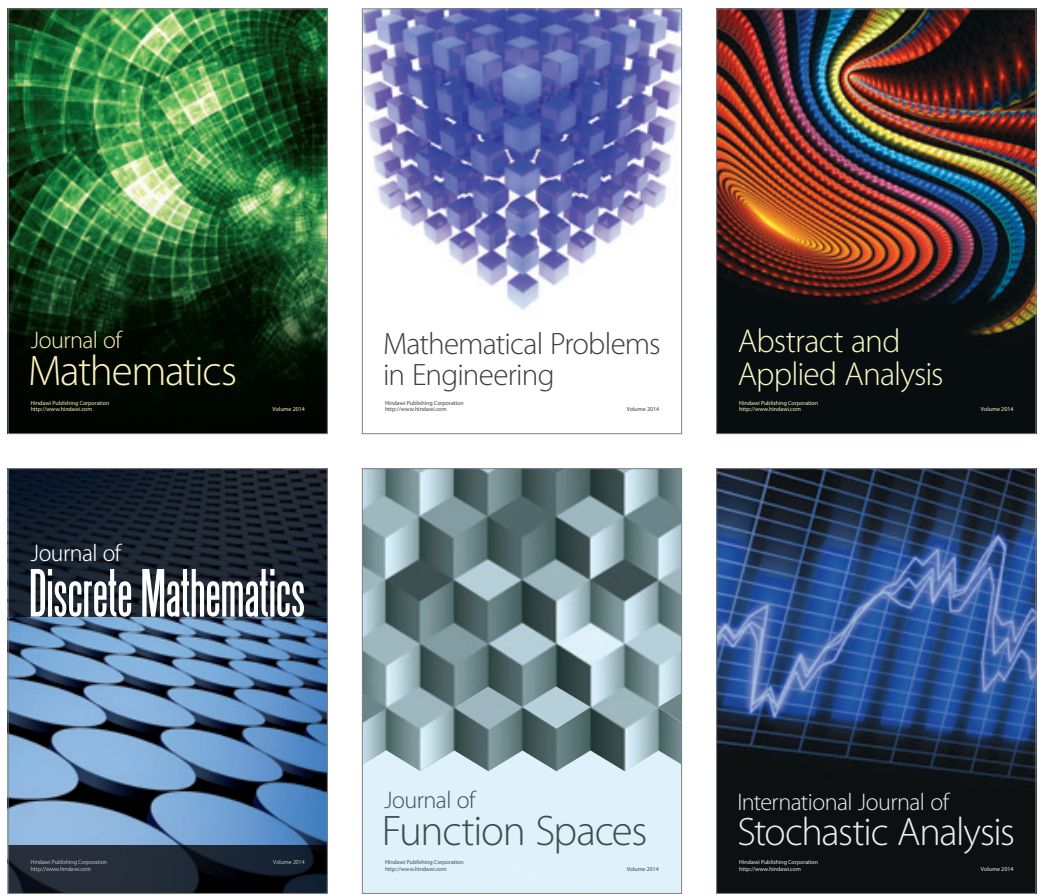

Journal of

Function Spaces

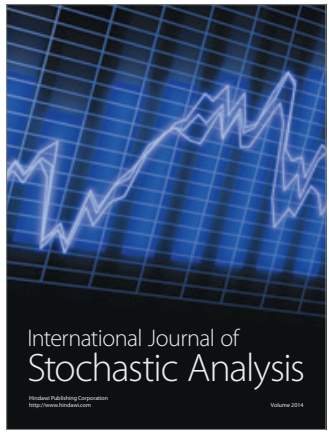

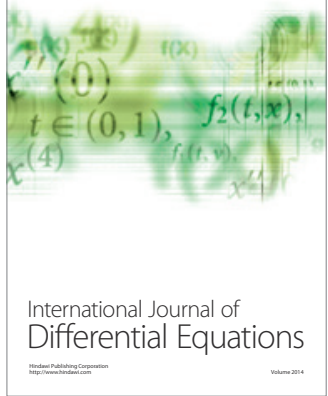
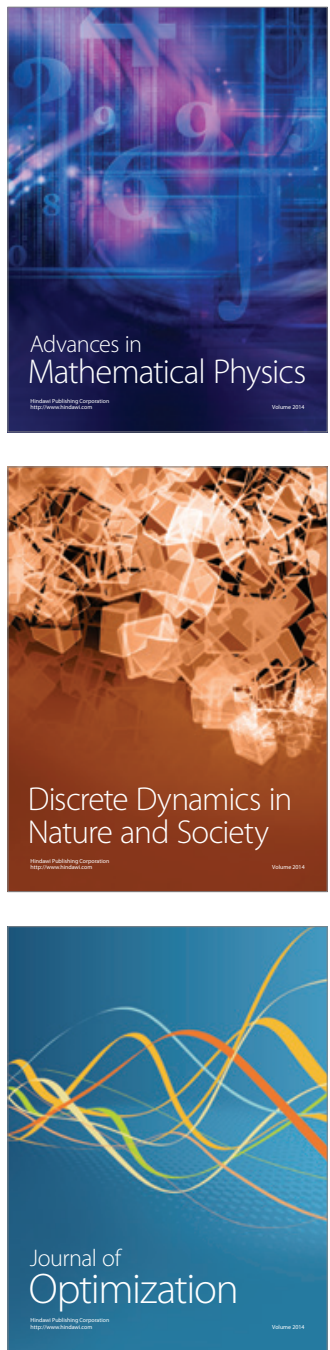